3. Оценить техническую готовность и само наличие ПО;

4. Определить формат взаимодействия сотрудников в новых условиях;

5. Оценить возможные риски.

$$
* * *
$$

1. СЭД (рынок России). URL: https://www.tadviser.ru/index.php/Статья:СЭД_(рынок_России)

2. Исследование «Логики бизнеса» и IDC: потенциал для дальнейшего внедрения СЭД на российском рынке высок. URL: https://www.cnews.ru/news/line/2018-0417_issledovanie_logiki_biznesa_i_idc_potentsial

3. Тренды российского рынка СЭД/ECM. https://www.tadviser.ru/index.php/Статья:Тренды_российского_рынка_СЭД/ЕСМ-систем

4. Технологии и инструменты для удаленной работы с документами. URL: https://eos.ru/eos_calendar/detail.php?ID=30632

5. Паспорт национального проекта «Национальная программа «Цифровая экономика Российской Федерации» (утв. президиумом Совета при Президенте РФ по стратегическому развитию и национальным проектам, протокол от $04.06 .2019 \quad$ №7). http://www.consultant.ru/document/cons_doc_LAW_328854/

\title{
Марченко А.B. \\ Новый вид привычного: влияние VR/AR на существующую реальность
}

Государственный университет управления (Россия, Москва)

doi: 10.18411/lj-04-2021-14

\section{Аннотация}

Данная статья посвящена рынку VR/AR технологий: его текущему состоянию, тенденциям развития и вкладу в существующую действительность. Целью написания статьи является исследование изменений сферы VR/AR, выявление дальнейших направлений её развития. Для написания статьи было проведено вторичное исследование российских и зарубежных источников. В результате автором были представлены некоторые рекомендации по дальнейшему развитию сферы VR/AR.

Ключевые слова: VR, AR, современные технологии, влияние новых технологий, VR/AR в рекламе, тенденции развития.

\section{Abstract}

The article is devoted to the market of VR/AR technologies: its current condition, development trends and contribution in present reality. The main purpose of the article is exploring changes of VR/AR market, revealing further trends of developing. Secondary research of Russian and overseas sources was done for writing. As a result of this work, there was presented some recommendations for further development of VR/AR sphere.

Keywords: VR, AR, modern technologies, influence of modern technologies, VR/AR in advertising, development trends

На данный момент технический прогресс не замедляется ни на секунду. Плоды этого прогресса находятся буквально сплошь и рядом, что уже становится трудно представить жизнь без них. И то, что когда-то казалось чем-то невозможным и встречающимся исключительно в фантастике, теперь становится доступно каждому. Это же касается стремительно набирающих обороты виртуальной (VR) и дополненной (AR) реальностей. Но, несмотря на все достижения сферы информационных технологий и перспективы применения, открывающимися перед пользователями, появляются и новые трудности, с которыми необходимо бороться. Так что же представляет собой сфера VR/AR сейчас?

O проявлении высокого интереса к данной отрасли говорит текущее состояние рынка VR и AR технологий. В первую очередь, глобальный рынок виртуальной 
реальности отличается стремительным ростом, который составляет 78,5\% по сравнению с предыдущим годом и оценивается в 16,8 млрд. долларов, что говорит нам о быстром развитии технологий. Более того, о высоком спросе на VR-девайсы говорит и количество пользователей по всему миру, которое уже превысило оценку в 200 млн. человек, в то время как в 2014 их количество не превышало 200 тыс. человек [1]. Наибольшие же расходы на AR и VR технологии приходятся на США (6,6 млрд. долларов) и Китай (6 млрд. долларов), в то время как в Японии и Западной Европе они составили только 1,76 млрд. долларов [2].

На высокий спрос девайсов также указывает то, что всё больше людей по всему миру стремятся опробовать погружение в другой мир у себя дома. Не стал исключением и венгерский поклонник VR Лукас: «на первый взгляд, погружаться в другой мир было очень круто и захватывающе, но уже через некоторое время это яркое впечатление проходит». По словам Лукаса, всё дело в нашем организме. Он не приспособлен к тому, чтобы сидеть в VR-шлеме более 30 минут. Если всё-таки просидеть больше, могут начать болеть глаза, и, ко всему прочему, в некоторых играх может буквально стошнить. Помимо этого, графика тоже имеет свои минусы: из-за низкого разрешения картинка выглядит размытой, что преграждает путь полному погружению. Помимо тошноты и головокружения, продолжительное использование шлема виртуальной реальности может на довольно долгое время выбить человека из колеи. Игра не может симулировать реальность полностью, поэтому по выходе из нее люди сталкиваются с такими сложностями, как проливание жидкостей мимо рта или проблемы с координацией и ориентацией в пространстве. Что хорошо, так это то, что такой эффект кратковременен и возникает только у «засидевшихся» игроков. Кроме этого, из-за слабого технического оснащения потребителей, трудности в продвижении и влиянии на целевую аудиторию возникают и у товаропроизводителей и других крупных брендов, которые пока не могут в полной мере воздействовать на своих клиентов, применяя технологии виртуальной и дополненной реальностей.

Выходит так, что нынешние шлемы ещё далеки от идеала, а заявленная разработчиками другая реальность дома недостаточно реальна. Ведь, чтобы погружение было полным необходимо иметь высокотехнологичное оборудование, быстрый интернет, качественно воздействовать на органы осязания человека, позволить полноценно входить в контакт со всеми предметам, с помощью различных контроллеров и датчиков, и свободно существовать в другом пространстве, что, например, можно сделать в существующих развлекательных локациях (Location-based Entertainment) [3].

Тем не менее, люди и раньше пытались погрузиться в какой-то другой мир, увидеть то, что никогда не было доступным. Поэтому, в середине 20 века был создан первый в мире стереоскоп, который стал прототипом современных VR шлемов и очков. Его механизм был прост: с помощью линз, установленных под углом, картинки становились объёмными. Теперь же, благодаря техническому прогрессу, мы можем видеть не просто объёмные картинки, а по-настоящему «погрузиться» в другую реальность, двигаться и взаимодействовать в ней.

Однако данные девайсы не только созданы для развлечений, они также активно используются и в других сферах жизни: в учёбе, бизнесе. Теперь архитекторам и дизайнерам не составляет особого труда визуализировать свои труды, увидеть их изнутри. А студенты медицинских колледжей и вузов могут пройти практику некоторых серьёзных операций, которые провести раньше не представлялось возможным. Изменения коснулись и сферы потребления. Товаропроизводители теперь предлагают получить бонусом к своим товарам не просто пробники или «ложки» в подарок, а возможность развлечения с помощью дополнительной реальности или, например, показывают, как самостоятельно можно сделать стереоскоп. Что же касается 
более дорогих компаний, таких как производители автомобилей, сейчас они могут демонстрировать машины в режиме виртуальной реальности.

Так, польза от применения современных VR-технологий уже стала заметна: $82 \%$ компаний, применяющих VR в своей деятельности, заявили, что преимущества значительно превышают ожидания. Особенно высоки перспективы дальнейшего развития в ремонте и строительстве. Например, в инженерной индустрии с применением технологий виртуальной реальности сократилось время разработки моделей на $10 \%$, а время строительства на $7 \%$. А с адаптацией виртуальной реальности в электронную коммерцию, конверсия онлайн-шоппинга увеличилась на $17 \%$. И это далеко не все возможные выгоды, которые даёт виртуальная и дополнительная реальность: 20\% покупателей заявили, что использование VR и AR повысит лояльность к компаниям и их брендам. Кроме того, VR-технологии хорошо проявили себя и в отрасли туризма: 13\% людей, пробующих путешествовать в VR, бронировали тур или связывались с гостиницами после этого [1].

С появлением новых задач, которые призвана решить виртуальная реальность, появился и новый сегмент рынка технических приборов, который уже наполнился ведущими компаниями-конкурентами, среди которых Sony, HTC, Samsung, Oculus и Valve. Однако массовое пользование таких устройств ещё под вопросом, поскольку не каждый может позволить себе провести вечерок в другой реальности дома. В связи с этим появляются и новые тенденции развития устройств [4].

Таким образом, планируется сделать более модернизированные и бюджетные девайсы, которые будут пользоваться спросом. Прогнозируется, что результаты будут ошеломляющими: мировой размер рынка возрастёт от 27 млрд. долларов до 209 млрд. долларов до конца 2022 года; число AR/VR устройств, поставляемых по всему миру, увеличится до 68,6 млн. единиц, а AR/VR гарнитуры достигнут массовых продаж до 30 млн. единиц в год к концу 2023. В связи с этим, мировые вложения крупных компаний и брендов в VR контент и приложения достигнут 3,7 млрд. долларов уже в 2021 году. Пользователи VR-гарнитур, в свою очередь, также задают тенденции развития данной сферы. Около 77\% владельцев шлемов хотят быть более социально-вовлечёнными в VR в процессе использования, особенно это касается всевозможных интерактивных взаимодействий в играх, просмотра видео и вебинаров. В сфере же промышленного производства 43\% компаний заявили, что AR и VR станет мейнстримом в их организации в течение 3-5 лет [1].

Основной же целевой аудиторией рынка виртуальной реальности являются преимущественно мужчины - 30\% (в то время как женщины только $16 \%$ ), в возрасте от 16 до 34 лет. Большая часть из них считает, что в скоро времени VR станет мейнстримом, наибольший потенциал которого будет в игровом сегменте, поскольку $70 \%$ владельцев шлемов уже купили игры для них. Остальной же успех в применении VR-технологий будет замечен в маркетинге, рекламе, ритейле, строительстве и автомобильной промышленности [1]. Особенно выделяются возможности нейромаркетинга в маркетинговых исследованиях, где изучение сенсомоторной и когнитивной реакции на маркетинговые стимулы способствует «определению поведения покупателей, чтобы лучше понимать влияние психологических явлений и эмоций на выбор товаров», с целью повышения эффективности коммуникации с потребителями [8].

Так или иначе, эффект от применения VR/AR в рекламе и маркетинге уже сейчас можно проследить на многих каналах продвижения, в особенности, в Интернетпространстве, где использовать это не представляется сложным. Например, у всем известной IKEA существует отдельное AR-приложение, c помощью которого понравившуюся мебель можно «примерить» к своему дому. Для этого достаточно навести камеру гаджета на предположительное место расположения выбранного атрибута мебели, как он сразу же окажется там. Более того, многие автомобильные 
бренды также применяют возможности дополненной реальности на своих сайтах, позволяя пользователем просмотреть 3D-модель выбранной машины просто кликнув на неё [5].

Ситуация с телевидением, в свою очередь, обстоит несколько иначе: теперь выделяются другие интересные способы подачи информации. У зрителей появляется возможность вступать в контакт с новым иммерсивным контентом, становясь участниками событий. Пока такое можно увидеть только на площадках телеканалов в Интернете. К примеру, на канале ВВС существует исторический проект о лётчиках, где каждый может «сесть» в самолёт, участвующий в боевых действиях во время войны, и ощутить на себе всё, что видел и слышал пилот, загрузив проект в VR-очки Oculus или HTC Vive [6]. Но и это ещё не всё: предлагаются варианты того, как можно использовать AR в эфирном вещании. Так, закрытый телеканал Life в формате новостей применял технологии дополненной реальности, создавая для студии 3Dобъекты, о которых шла речь в выпуске. Таким образом, AR может менять наполнение студий, позволяя выстраивать взаимодействие с цифровыми объектами, что может стать новым вариантом Product Placement.

Что же касается печатной рекламы, в ней одной из первых нашли способ применения AR-технологий. Ещё в 2012 году читатели онлайн журналов могли увидеть как перед ними «оживали» обложки. Сейчас же взаимодействие как с офлайн, так и онлайн журналами стало более интерактивным. Каждая страница печатного издания при желании может быть диджитальной. Самый простой и надежный способ сделать это - нанести AR-маркер на страницу, к которому относится и обычный QR-код. Так, в сентябрьском номере Cosmopolitan многие страницы были прокодированы, а к кодам были прикреплены видеоматериалы. Другими словами, любой объект в журнале легко может стать ссылкой, а сам физический журнал - использовать все доступные интернету форматы контента.

Всё, что есть в городском пространстве, теперь может стать цифровым носителем, что открывает перспективы для развития наружной рекламы. Предпосылки к применению AR в городах появились после запуска нашумевшей игры Pokémon Go, в которой размещение объектов в привязке к точкам в пространстве увлекло людей. Этот же принцип использовался и в рекламной кампании ко дню города сервиса «Яндекс. Карты» в Москве, где в разных точках города можно было найти виртуальных персонажей: Неваляшку возле Центрального детского магазина, гигантское мороженое возле Парка Горького [7].

Исходя из всего вышеперечисленного, можно подытожить, что рынок VR/AR технологий пользуется высокой популярностью и выделяется особыми перспективами развития. Однако из-за слаборазвитого технического оснащения потребителей и слишком дорогостоящих девайсов и контроллеров, которые были бы качественны в использовании, с трудностями в применении этих технологий сталкиваются как сами потребители, так и крупные компании и рекламопроизводители. В соответствии с этим, рынок продолжает развиваться и совершенствовать свои технологии, предлагая всё более технологичные и доступные устройства и другие оснащения, чтобы вскоре их применение стало чем-то простым и повседневным. Поэтому, всё, что сейчас требуется - дать рынку VR/AR технологий некоторое время, чтобы насладиться всеми его преимуществами в ближайшем будущем.

Таким образом, приводя всё вышесказанное к сведению, можно сделать вывод, что у рынка VR/AR технологий есть огромный потенциал, который уже оценили не только заядлые игроки, но и крупные торговые компании, и популярные бренды. Даже несмотря на все возникающие трудности, потребители не перестают верить, что когдато виртуальная реальность сможет стать неотъемлемой частью жизни, сделав её 
намного ярче и интереснее. В связи с бешеными темпами технического прогресса, ждать придётся совсем недолго.

$$
* * *
$$

1. Онлайн-ресурс о технической индустрии TеchJury - Режим доступа: https:/techjury.net/blog/virtualreality-statistics/

2. Онлайн-ресурс о технике Kommando Tech - Режим доступа: https://kommandotech.com/statistics/virtual-reality-statistics/

3. Журнал Forbes - Режим доступа: https://www.forbes.com/sites/moorinsights/2019/01/04/locationbased-vr-the-next-phase-of-immersive-entertainment/?sh=31f106ea3f57

4. Онлайн-портал о бизнесе и технологиях vc.ru - Режим доступа: https:/vc.ru/future/1 10266-trendy2020-vr-realnost-kotoroy-net

5. Новостной портал о рекламе и маркетинге Sostav - Режим доступа: https://www.sostav.ru/publication/ar-vr-v-reklame-kak-ispolzovat-novyj-opyt-v-kommunikatsii-spotrebitelem-34312.html

6. Телерадиовещательная компания $\mathrm{BBC}-1$ Режим доступа: https://www.bbc.co.uk/history/worldwars/wwone/launch_vt_dogfight.shtml

7. Поисковая система Яндекс - Режим доступа: https://yandex.ru/promo/maps/ar-moscow

8. Vasilyeva O.A. Neuromarketing Technologies in the Advertising Industry. Наука и бизнес: пути развития, № 10 (100) 2019 - с. 151-153

\section{Мелитонян М.С., Фешина Е.В. \\ Discord как средство онлайн общения и его преимущества среди других мессенджеров}

ФГБОУ ВО «Кубанский государственный аграрный университет имени И.Т. Трубилина»

(Россия, Краснодар)

doi: 10.18411/lj-04-2021-15

\section{Аннотация}

В данной статье рассматриваются вопросы работы Discord в двух режимах. Раскрыт возможный функционал каждого режима, возможности мессенджера, описаны специальные возможности Discord.

Ключевые слова: мессенджер, функционал, функции, бот, чат, канал.

\section{Abstract}

This article discusses how Discord works in two modes. The possible functionality of each mode, the capabilities of the messenger is revealed, the special features of Discord are described.

Keywords: messenger, functionality, functions, bot, chat, channel

Из-за популярности социальных сетей и актуальности онлайн-общения постоянно появляются новые мессенджеры. Одним из таких является Discord. Появился он на просторах интернета в 2015 году и стал наиболее популярным у киберспортсменов и учащихся и это вполне объяснимо, поскольку у сервиса много интересных функций и возможностей, которыми он выигрывает у других бесплатных мессенджеров, у таких как Skype, What's up, Viber и других. различия.

Discord имеет два режима: «обычный» и «сервер», имеющих некоторые

Наличие функционала в «обычном» режиме позволяет поддерживать основные языки миры, показывать видео с экрана с разрешением $720 \mathrm{p}$, отправлять файлы до 8 МБ (без подписки Nitro), отправлять сообщения до 2000 символов, имеется возможность создавать групповые чаты. Помимо этого «обычный» режим имеет поддержку на нескольких операционных системах, таких как Linux, macOS, Windows, 